This is an electronic reprint of the original article. This reprint may differ from the original in pagination and typographic detail.

Author(s): Ngumba, Elijah; Kosunen, Päivi; Gachanja, Anthony; Tuhkanen, Tuula

Title: A multiresidue analytical method for trace level determination of antibiotics and antiretroviral drugs in wastewater and surface water using SPE-LC-MS/MS and matrixmatched standards

Year: $\quad 2016$

Version:

Please cite the original version:

Ngumba, E., Kosunen, P., Gachanja, A., \& Tuhkanen, T. (2016). A multiresidue analytical method for trace level determination of antibiotics and antiretroviral drugs in wastewater and surface water using SPE-LC-MS/MS and matrix-matched standards. Analytical Methods, 8(37), Article 6720-6729.

https://doi.org/10.1039/C6AY01695B

All material supplied via JYX is protected by copyright and other intellectual property rights, and duplication or sale of all or part of any of the repository collections is not permitted, except that material may be duplicated by you for your research use or educational purposes in electronic or print form. You must obtain permission for any other use. Electronic or print copies may not be offered, whether for sale or otherwise to anyone who is not an authorised user. 


\title{
Multiresidue analytical method for trace level determination of antibiotics and antiretroviral drugs in wastewater and surface water using SPE-LC-MS/MS and matrix-matched standards
}

Elijah Ngumba*a $^{\mathrm{a}}$, Päivi Kosunen ${ }^{\mathrm{a}}$ Anthony Gachanja $^{\mathrm{b}}$ and Tuula Tuhkanen ${ }^{\mathrm{a} \dagger}$

\begin{abstract}
An analytical method for simultaneous determination of seven commonly used antibiotics and three antiretrovirals in surface water and urban wastewater at $\mathrm{ng} / \mathrm{L}$ level has been developed. The method involves concentration and clean-up by solid phase extraction (SPE) followed by identification and quantification by liquid chromatography tandem mass spectrometry (LC-ESI-MS/MS). The use of matrix-matched calibration curves constructed by spiking surface water was evaluated for quantification and compared with the internal standard method using isotopically labelled compounds. The method gave absolute recoveries of $41-116 \%$ with most of the compounds having recoveries $>50 \%$. The LOQ ranged from 5-63 ng/L allowing for determination of the analytes at trace levels in the environmental samples considered. The difference in the quantification results obtained using surface water matrix-matched standards and internal standards were within $\pm 20 \%$ margin. The method provides an affordable and relatively fast alternative with acceptable accuracy and precision. The method was applied to study the occurrence of the target analytes in surface water of Lake Päijänne and wastewater from Jyväskylä wastewater treatment plant (WWTP) in Central Finland. All target compounds were detected in the WWTP streams with concentration ranging between 10-570 ng/L while low ng/L levels were measured for some of the analytes in surface waters. The results institutes the need for further monitoring in in other WWTP streams and receiving waters as well as improvements of the wastewater treatment process with the aim of minimizing the pharmaceutical load in the effluents.
\end{abstract}

\section{Introduction}

Antibiotics and antiretroviral drugs are some of the emerging contaminants that have received increased attention due to their potential negative effects to the environment. Studies have shown that after consumption, they are largely excreted into the environment unchanged or as fractions of their various metabolites ${ }^{1-5}$. The concern over the release of these drugs into the environment majorly emanates from their potential harm such as antimicrobial resistance as well as toxicity sensitive aquatic organisms ${ }^{6-9}$. Pharmaceuticals compounds are not removed entirely during wastewater treatment process and as a result, WWTPs have been indicated as

\footnotetext{
$\dagger$

${ }^{a}$ University of Jyvaskyla, Department of Biological and Environmental Science, P.O. Box 35, FI- 40014 University of Jyvaskyla, Finland

${ }^{b}$ Jomo Kenyatta University of Agriculture and Technology, Department of Chemistry, P.O. Box 62000-00200 Nairobi, Kenya

Electronic Supplementary Information (ESI) associated with this article can be found in the online version available
} 
a major entry route of pharmaceuticals and personal care products (PPCPs) to the environment ${ }^{10-13}$.

Presently, only a few studies are available on the occurrence and fate of antiretroviral drugs in the environment. However, since the discovery of human immunodeficiency virus (HIV) in 1983, there has been dramatic growth in the consumption of anti-HIV drugs and as of 2012, some 9.7 million people worldwide were under antiretroviral therapy of which an estimated 7.5 million people were in Africa; which bears the highest burden of HIV infections. In this regard, various antiretroviral and antibiotic regimens are used to manage HIV and other HIV induced infections ${ }^{14,15}$. Due to low HIV prevalence in developed countries, analyses of antiretroviral drugs have not yet received a lot of attention but recent studies in Belgium and Germany have documented environmentally significant concentrations in both surface waters and WWTP effluents ${ }^{16,17}$.

The use of electrospray ionization tandem mass spectrometry for detection and quantification of PPCPs in environmental samples is usually associated with significant matrix effects ${ }^{18}$. Matrix effects emanates from the competition between endogenous sample components coeluting with the analyte leading to decreased or increased efficiency in the formation of the analyte ion ${ }^{19-21}$. As a result external calibration methods using pure standards dissolved in the mobile phase usually lead to over-estimation or underestimation of analyte concentration due to matrix effect signal suppression or enhancement. To compensate for the matrix effects, internal standards (IS), matrix-matched standards and standard addition methods have been used. The IS method of calibration incorporating isotopically labelled standards is usually the most preferred since its simple, quick and efficient. However, isotopically labelled IS are usually costly and sometimes not commercially available making the method inaccessible to many users ${ }^{22,23}$. The method of standard addition has major limitations in that it is labour intensive and requires large sample volumes hence can only be used effectively when the number of samples to be analysed is low ${ }^{24}$. Matrix-matched calibration is also labour intensive but high sample throughput can be efficiently realized.

The aim of the present study was to develop of a relatively cheap and reliable multiresidue SPE-LC-ESI-MS/MS method for analysis of antiretroviral and antibiotic compounds in urban hydrological cycle. In this study, three antiretrovirals (nevirapine (NVP), zidovudine (ZDV) and lamivudine (3TC)) and seven antibiotics; trimethoprim (TMP), sulfamethoxazole (SMX), ciprofloxacin (CIP), norfloxacin (NOR), tetracycline (TET), doxycycline (DOX) and amoxicillin (AMO) were selected for analysis based on the consumption data for Finland (Table 1). The results presented here include an evaluation of the accuracy of the results quantified using surface water matrix-matched calibration compared to internal standard calibration. 
Table 1: Selected pharmaceuticals and some of their properties

\begin{tabular}{|c|c|c|c|c|c|}
\hline Compound & CAS NO. & $\begin{array}{l}\text { Water } \\
\text { solubility } \\
(\mathrm{mg} / \mathrm{L})^{1}\end{array}$ & $\mathrm{pKa}^{25-27}$ & $\begin{array}{l}\text { Excretion rate as } \\
\text { unchanged } \\
\text { compound }(\%)^{28-34}\end{array}$ & $\begin{array}{l}\text { Consumption } \\
\text { in } 2014 \\
\mathrm{~kg} / \text { year }^{35}\end{array}$ \\
\hline $\begin{array}{l}\text { Sulfamethoxazole } \\
\text { (SMX) }\end{array}$ & $723-46-6$ & 610 & $5.6,1.83$ & $15-25$ & 359 \\
\hline Ciprofloxacin (CIP) & $85721-33-1$ & 13500 & $6.4,8.2$ & 80 & 1198 \\
\hline Norfloxacin (NOR) & 70458-96-7 & 1010 & $5.77,8.68$ & 60 & 96 \\
\hline Doxycycline (DOX) & $564-25-0$ & 630 & 7.75 & 70 & 545 \\
\hline Tetracycline (TET) & $60-54-8$ & 1330 & 8.24 & $80-90$ & 1318 \\
\hline Amoxicillin (AMO) & $26787-78-0$ & 958 & $3.23,7.43$ & $60-80$ & 9367 \\
\hline Trimethoprim (TMP) & $738-70-5$ & 400 & $7.2,17.33$ & $80-90$ & 1055 \\
\hline Zidovudine (ZDV) & $30516-87-1$ & 20100 & 9.7 & $15-20$ & 12 \\
\hline Lamivudine (3TC) & $134678-17-4$ & 70000 & $4.3,14.29$ & 70 & 54 \\
\hline Nevirapine (NVP) & $129618-40-2$ & 0.7046 & 2.8 & 2.7 & 24 \\
\hline
\end{tabular}

${ }^{25}$ Wishart et al., 2006; ${ }^{26}$ Babić et al. 2007; ${ }^{27}$ US EPA and SRC 2012; ${ }^{28}$ Radke et al., 2009;

${ }^{29}$ Kasprzyk-Hordern et al., 2009; ${ }^{30}$ Harlass, 1996; ${ }^{31}$ Straub, 2013); ${ }^{32}$ Jjemba, 2006); ${ }^{33}$ Kumar et al., 2006; ${ }^{34}$ Riska et al., 1999; ${ }^{35}$ Finnish Medicines Agency, 2014

\section{Materials and methods}

\section{Chemicals and standards}

HPLC-grade methanol and acetonitrile were purchased from Merck (Darmstadt, Germany) and formic acid (98\%) from Fluka (Darmstadt, Germany). Glass microfiber filters $47 \mathrm{~mm}$ $\mathrm{GF} / \mathrm{D}(2.7 \mu \mathrm{m})$ and GF/F $(0.7 \mu \mathrm{m})$ were obtained from Whatman (Maidstone, England). All the pharmaceutical standards (purity $\geq 95 \%$ ) were a kind donation from Universal Corporation Ltd, Kenya. The ISs $\left[{ }^{2} \mathrm{H}_{8}\right]$-Ciprofloxacin, $\left[{ }^{2} \mathrm{H}_{4}\right]$-Sulfamethoxazole, $\left[{ }^{13} \mathrm{C},{ }^{2} \mathrm{H}_{3}\right]$ Zidovudine, $\left[{ }^{2} \mathrm{H}_{4}\right]$-Nevirapine, and $\left[{ }^{13} \mathrm{C}^{2} \mathrm{H}_{2}{ }^{15} \mathrm{~N}_{2}\right]$-Lamivudine were purchased from Alsachim (Illkirch, France) while $\left[{ }^{2} \mathrm{H}_{9}\right]$-Trimethoprim was purchased from Sigma-Aldrich (Steinheim, Germany). Ultrapure water was used throughout the study and was generated using Ultra Clear UV Plus and euRO 60 Reverse Osmosis unit (SG, Barsbuttel Germany). Unless otherwise indicated, all the chemicals used in the study were of analytical grade or above. Individual standard solutions were prepared at a concentration of $1000 \mathrm{mg} / \mathrm{L}$. Apart from ciprofloxacin which was dissolved in ultrapure water; all the other compounds were dissolved in methanol. The standards were subsequently diluted with $1: 1(\mathrm{v} / \mathrm{v})$ methanol/ ultrapure water to a pooled mixed standard of $10 \mathrm{mg} / \mathrm{L}$ as stock solution and stored at $+4^{\circ} \mathrm{C}$ in the dark.

\section{Sample collection}

Composite $24 \mathrm{~h}$ influent and effluent samples were collected from Jyväskylä wastewater treatment plant in the months of September 2015 and March 2016. In addition, grab water samples were collected from Lake Päijänne which receives the treated effluent from Jyväskylä WWTP (Figure 1). The samples from Lake Päijänne were collected at Hämeenlahti 
(A) and Konjakki (B) which are approximately $200 \mathrm{~m}$ and $4 \mathrm{~km}$ from discharge point, respectively. Jyväskylä WWTP receives an average of $35,000 \mathrm{~m}^{3}$ of waste water per day and serves a population of 150,000 . Grab surface water samples collected from Lake Jyväsjärvi were used as blanks in the study as the water was found not contain detectable levels of the target analytes. The samples were collected in $1 \mathrm{~L}$ high density polyethylene bottles and stored at $+4^{\circ} \mathrm{c}$ in the dark awaiting extraction within $48 \mathrm{~h}$.

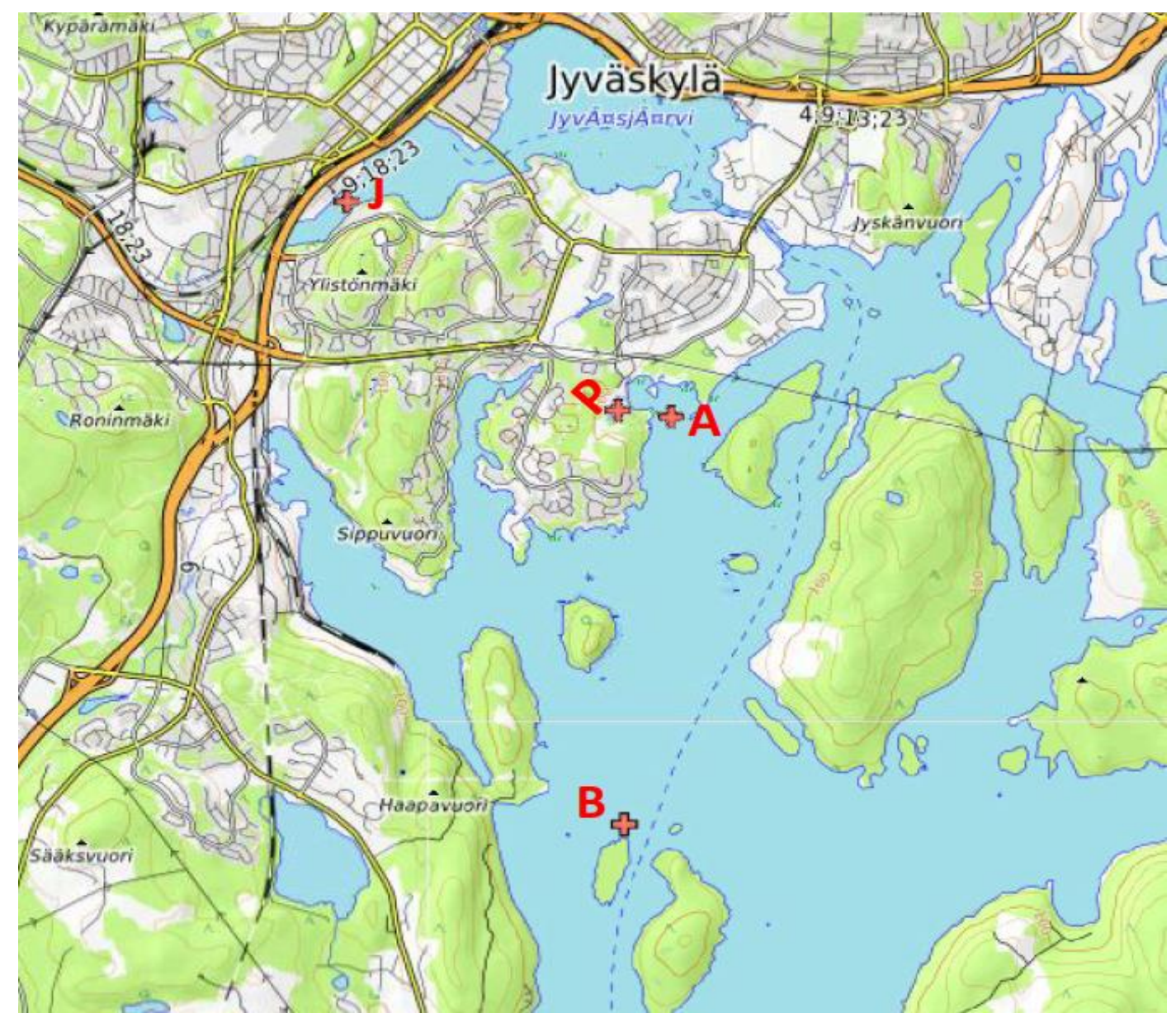

Figure 1: Map showing the sampling points: Hämeenlahti (A), Konjakki (B), WWTP (P) and Lake Jyväsjärvi (J)

\section{LC-MS/MS optimization}

\section{Liquid chromatography}

The analysis was performed with a Waters Alliance 2795 system consisting of tertiary pump, vacuum degasser, autosampler, and column oven (set to $30^{\circ} \mathrm{C}$ ). Compounds were separated with a reversed phase C18 column (Waters XBridgeTM $3.5 \mu \mathrm{m}, 2.1 \times 100 \mathrm{~mm}$ with $3.5 \mu \mathrm{m}$, $2.1 \times 10 \mathrm{~mm}$ guard column). The LC conditions were optimized with regard to the choice of mobile phase and the gradient conditions. To achieve this, methanol ( $\mathrm{MeOH})$ and acetonitrile $(\mathrm{ACN})$ were evaluated as the organic phase with ultrapure water as the aqueous phase. 


\section{Mass Spectrometry}

In the Quattro Micro triple-quadrupole mass spectrometer, nitrogen was used as desolvation gas $(500 \mathrm{~L} / \mathrm{h})$ and as cone gas $(50 \mathrm{~L} / \mathrm{h})$. Desolvation temperature and source temperature were $200^{\circ} \mathrm{C}$ and $100^{\circ} \mathrm{C}$ respectively. Argon was used as a collision gas at a pressure of $2.8 \times 10^{-4}$ mBar. Mass spectrometric analysis was performed in the positive electrospray ionization mode (ESI+) and the spectrometer operated in multiple reaction monitoring (MRM) with a dwell time and interchannel delay of $200 \mathrm{~ms}$. Precursor and product ions, collision energies, and cone voltages were optimized for each analyte. This was done by continuously infusing 5 $\mathrm{mg} / \mathrm{L}$ of pure analytes dissolved in 1:1 MeOH/ultrapure water (v/v) to the MS/MS system using the syringe pump at a flow rate of $10 \mu \mathrm{L} / \mathrm{min}$. The most abundant transition for each analyte was used for quantification. To determine the instrumental repeatability, the equipment was tested by injecting mixed replicate standards $(n=6)$ at three concentration levels (40, 200 and $1000 \mu \mathrm{g} / \mathrm{L})$ within the same day and between different days and evaluated based the relative standard deviations. Instrumental detection and quantification limits (IDL and IQL) were determined using pure standards dissolved in the mobile phase and were defined as the lowest concentration producing a signal-to-noise ratio of 3 and 10 respectively.

\section{Solid phase extraction (SPE)}

SPE was carried out using Oasis hydrophilic-lipophilic balance (HLB) cartridges (3 cc/60 $\mathrm{mg}, 6 \mathrm{cc} / 200 \mathrm{mg}$ ), strong cation exchange (MCX) and strong anion exchange (MAX) cartridges $(3 \mathrm{cc} / 60 \mathrm{mg}$ ). The SPE procedure consisted of 4 steps that included conditioning, loading, washing and elution. Cartridges were preconditioned with $\mathrm{MeOH}$ followed by ultrapure water then loaded at a flow rate of approximately $10 \mathrm{~mL}$ per min using SPE vacuum manifold (Supelco, Bellefonte, PA, USA) and dried in vacuum for 5 minutes. After drying, the cartridges were washed with ultrapure water and dried for a further 10 minutes before elution. All eluted extracts were evaporated in a stream of nitrogen at $40^{\circ} \mathrm{C}$ and reconstituted with $1 \mathrm{~mL}$ of $\mathrm{H}_{2} \mathrm{O} / \mathrm{ACN} 80 / 20$ (v/v) followed by filtration through $0.2 \mu \mathrm{m}$ cellulose acetate syringe filter before injection into LC-MS/MS system. SPE was optimized with regard to the sorbent, elution solvent, elution volume and sample $\mathrm{pH}$ (detailed steps provided in the supplementary material). Apart from SPE sorbent material that was optimized by extracting ultrapure water spiked with the target analytes, all the other parameters were optimized using spiked surface water that had no detectable quantities of the target analytes. The recovery for each step was evaluated by comparing the SPE extracted samples to non-extracted standard solutions that represented the theoretical maximum concentration.

\section{Method Validation}

The analytical parameters evaluated in the SPE-LC-ESI-MS/MS method included calibration, recovery, repeatability, limit of detection (LOD) and limit of quantification (LOQ). LOD and LOQ were defined as the lowest concentration producing a signal-to-noise ratio of 3 and 10 respectively ${ }^{36}$. Two separate matrix-matched calibration curves (11 points) were prepared by spiking surface water $(500 \mathrm{~mL}$ and $200 \mathrm{~mL}$ that corresponded to the volumes of surface water and WWTP influent/effluents to be extracted) with the target analytes at concentrations between $10 \mathrm{ng} / \mathrm{L}-5000 \mathrm{ng} / \mathrm{L}$ and subjecting them to the optimized SPE process. Parallel 7point calibration curves for quantification of the same target compounds using IS was constructed at concentration ranging from $10 \mu \mathrm{g} / \mathrm{L}-1000 \mu \mathrm{g} / \mathrm{L}$ target analytes dissolved in the mobile phase and fortified with $400 \mu \mathrm{g} / \mathrm{L}$ mixed ISs. Method interday repeatability expressed 
as relative standard deviation (RSD, \%) was evaluated by triplicate SPE extraction of spiked surface water in three alternate days.

In determination of the recovery, duplicate sets of $500 \mathrm{~mL}$ sample of surface water that had no detectable quantities of the analytes were spiked at $0.1 \mu \mathrm{g} / \mathrm{L}, 0.5 \mu \mathrm{g} / \mathrm{L}$ and $2 \mu \mathrm{g} / \mathrm{L}$ with the target analytes and extracted with Oasis HLB (6 cc, $200 \mathrm{mg})$ cartridges. The recoveries were evaluated by comparing the peak area obtained with post extraction spiked surface water (Equation 1). The post extraction recovery spike was prepared by subjecting surface water to the SPE process and spiking them with the corresponding concentration for the three experimental levels after the elution process. Similarly, the recovery in the WWTP influent/effluent was evaluated by a modified surrogate recovery method (synonymous to method of standard addition) as described by IUPAC ${ }^{37}$. To achieve this, $200 \mathrm{~mL}$ WWTP effluent/influent sample was used and the recovery computed as illustrated in Equation 2. The modification allows the matrix effect to be incorporated in the recovery computation.

Recovery $(\%)=\frac{C}{D} X 100(1)$

Where $\mathrm{C}$ is the peak area determined after extraction of the spiked water and $\mathrm{D}$ is the peak area for the corresponding matrix-matched standard.

Recovery $(\%)=\frac{C-E}{D-E} X 100(2)$

Where $\mathrm{C}$ is the peak area obtained after extraction of the surrogate spiked WWTP effluent/influent, $\mathrm{D}$ is the peak area for the corresponding wastewater spiked after extraction and $\mathrm{E}$ is the peak area obtained after extraction of the non-spiked wastewater.

Matrix effect (ME) was evaluated using Equation 3, as described in the literature ${ }^{18}$

$\boldsymbol{M E}(\%)=\left(\frac{B}{A}-1\right) \times 100(3)$

Where $\mathrm{A}$ is the peak area of the analyte determined for the standard solution and B is the peak area of the analyte determined for the surface water spiked with the analyte after SPE. Matrix effect of 0 is obtained when no matrix effects are present in the sample while ME >0 (positive values) and $\mathrm{ME}<0$ (negative values) signify signal enhancement and suppression, respectively.

\section{Matrix-matched VS the IS quantification method and application to real samples}

The extraction of samples was carried out using the optimized SPE procedure. Prior to extraction, the samples were double filtered through $47 \mathrm{~mm} \mathrm{GF} / \mathrm{D}(2.7 \mu \mathrm{m})$ and GF/F $(0.7$ $\mu \mathrm{m})$ glass microfiber filters (Whatman, Maidstone, England) to remove the suspended particles that would otherwise clog the SPE cartridges. For optimum analyte recovery 500 $\mathrm{mL}$ of surface water and $200 \mathrm{~mL}$ of WWTP influent and effluent were extracted using Oasis HLB (6 cc, $200 \mathrm{mg}$ ). To all samples, $40 \mu \mathrm{L}$ of $10 \mathrm{mg} / \mathrm{L}$ mixed ISs were added prior to SPE process. Procedural blanks consisting of ultrapure water spiked with internal standards were run as controls for contamination during sample processing.

To establish the possibility of using surface water matrix-matched standards for the simultaneous analysis of surface waters and WWTP influent/effluent, non-spiked as well as spiked samples were analyzed and quantified by matrix-matched and IS constructed 
calibrations. However, the comparison of the two methods was not possible for AMO, DOX and TET since there were no appropriate internal standards available. Relative error (\%) was computed for the water matrices using the internal standard quantification results as the reference value (Equation 4).

Relative Error $(\%)=\frac{C_{M M}-C_{I S}}{C_{I S}} \times 100(4)$

Where $\mathrm{C}_{\mathrm{MM}}$ and $\mathrm{C}_{\mathrm{IS}}$ are the concentrations found using the matrix-matched and internal standard calibrations, respectively.

\section{Results and Discussion}

\section{Optimization of LC-MS/MS}

A number of experiments were conducted in order to achieve optimum chromatographic separation for all the analytes. Waters C18 reverse phase column was selected based on its versatility in use. Several mobile phase combinations were evaluated using ACN and methanol as the organic phase and Ultrapure water as the aqueous phase. The use of methanolic mobile phase resulted to peak tailing coupled by sample carry over and as a result methanol was abandoned as a mobile phase. In summary, the selected mobile phase consisted of ACN (B) and Ultrapure water (A) both containing $0.1 \%(\mathrm{v} / \mathrm{v})$ formic acid. The flow rate of $0.25 \mathrm{~mL} / \mathrm{min}$ was used and an injection volume of $10 \mu \mathrm{L}$. The gradient of B was held at $20 \%$ in the first 2 minutes then linearly increased to $100 \%$ in 3 minutes. The amount of ACN was then lowered back to $20 \%$ between 5-10 minutes and held there for 2 minutes. The column was then equilibrated for 2 minutes before the next injection. The retention times for all the compounds are as illustrated in Table 2 and a variation of \pm 0.1 minutes in retention time was considered acceptable. Chromatograms showing the MRM transitions for the matrix-matched standards can be found in the electronic supplementary material (Figure S1)

ESI-MS/MS parameters were optimized by direct infusion of the individual analyte standard solution using a syringe pump. For all the compounds, positive ionization was selected since the compounds were either neutral or weak bases and thus the precursor ion was $[\mathrm{M}+\mathrm{H}]^{+}$. The intraday and interday instrumental precision (repeatability) was evaluated by injecting mixed standards dissolved in the mobile phase $(n=6)$ at three concentration levels. The precision was evaluated by RSD of the response (Table S2 in the supplementary material). The RSD for all compounds ranged from $2-10 \%$ and $3-12 \%$ for intraday and interday, respectively. Since RSD values were below $15 \%$ the instrumental precision was considered acceptable ${ }^{36}$. Instrumental detection and quantification limits are presented in Table $\mathrm{S} 4$ and ranged from $0.9-7.6 \mu \mathrm{g} / \mathrm{L}$ and $3.3-23.3 \mu \mathrm{g} / \mathrm{L}$, respectively demonstrating that sample concentration step was required for quantification of the analytes in the $\mathrm{ng} / \mathrm{L}$ range. 
Table 2: Optimum LC-ESI-MS/MS conditions for the analysis of antibiotics and antivirals in Surface water

\begin{tabular}{|c|c|c|c|c|c|c|}
\hline Compound & IS $^{1}$ & $\begin{array}{l}\text { Precursor } \\
\text { ion }(\mathrm{CV})^{2}\end{array}$ & $\begin{array}{l}\text { Quantifier } \\
\text { ion }(\mathrm{CE})^{3}\end{array}$ & $\begin{array}{l}\text { Qualifier } \\
\text { ion } \\
(\mathrm{CE})\end{array}$ & $\mathrm{RT}^{4}$ & $\begin{array}{l}\text { Ion } \\
\text { Ratio }^{5}\end{array}$ \\
\hline CIP & {$\left[{ }^{2} \mathrm{H}_{8}\right]-\mathrm{CIP}$} & $332.1(34)$ & $288.0(19)$ & $314.1(19)$ & 2.2 & 2.5 \\
\hline$\left[{ }^{2} \mathrm{H}_{8}\right]-\mathrm{CIP}$ & - & $340.4(34)$ & 296.1 (19) & $322.1(19)$ & 2.2 & 2.1 \\
\hline NOR & {$\left[{ }^{2} \mathrm{H}_{8}\right]-\mathrm{CIP}$} & $320.3(30)$ & $276.0(18)$ & $302.0(25)$ & 2.1 & 2.4 \\
\hline SMX & {$\left[{ }^{2} \mathrm{H}_{4}\right]-\mathrm{SMX}$} & $254.0(28)$ & $156.0(18)$ & $108.0(17)$ & 5.1 & 2.5 \\
\hline$\left[{ }^{2} \mathrm{H}_{4}\right]-\mathrm{SMX}$ & - & $258.2(28)$ & $159.9(18)$ & $111.9(17)$ & 5.1 & 3.2 \\
\hline TMP & {$\left[{ }^{2} \mathrm{H}_{9}\right]-\mathrm{TMP}$} & $291.1(34)$ & $123.0(19)$ & $230.0(19)$ & 2.1 & 1.1 \\
\hline$\left[{ }^{2} \mathrm{H}_{9}\right]-\mathrm{TMP}$ & - & $300.4(34)$ & $264.1(26)$ & $234.1(26)$ & 2.1 & 1.1 \\
\hline DOX & - & $445.4(30)$ & $428.0(25)$ & $410.1(25)$ & 5.8 & 5.3 \\
\hline TET & - & $445.0(25)$ & $154.0(25)$ & $410.0(20)$ & 2.6 & 1.0 \\
\hline AMO & - & $365.9(15)$ & 113.9 (19) & $348.9(9)$ & 2.3 & 1.6 \\
\hline $3 \mathrm{TC}$ & {$\left[{ }^{13} \mathrm{C}^{2} \mathrm{H}_{2}{ }^{15} \mathrm{~N}_{2}\right]-3 \mathrm{TC}$} & $229.9(17)$ & $112.0(18)$ & $95.0(29)$ & 1.5 & 7.3 \\
\hline $\begin{array}{l}{\left[{ }^{13} \mathrm{C}^{2} \mathrm{H}_{2}{ }^{15} \mathrm{~N}_{2}\right]-} \\
\text { 3TC }\end{array}$ & - & $235.2(17)$ & $115.0(18)$ & $97.0(29)$ & 1.5 & 12.8 \\
\hline ZDV & {$\left[{ }^{13} \mathrm{C},{ }^{2} \mathrm{H}_{3}\right]-\mathrm{ZDV}$} & $268.2(16)$ & $127.0(17)$ & $110.1(25)$ & 2.3 & 9.2 \\
\hline$\left[{ }^{13} \mathrm{C},{ }^{2} \mathrm{H}_{3}\right]-\mathrm{ZDV}$ & - & $272.1(16)$ & 130.9 (17) & $113.9(25)$ & 2.3 & 13.6 \\
\hline NVP & {$\left[{ }^{2} \mathrm{H}_{4}\right]-\mathrm{NVP}$} & $267.2(40)$ & $226.2(29)$ & $198.0(29)$ & 4.1 & 3.4 \\
\hline$\left[{ }^{2} \mathrm{H}_{4}\right]-\mathrm{NVP}$ & - & $271.2(40)$ & $230.0(29)$ & $202.0(29)$ & 4.1 & 5.6 \\
\hline
\end{tabular}

${ }^{1}$ IS: Internal Standard; ${ }^{2} \mathrm{CV}$ : Sample Cone Voltage in Volts; ${ }^{3} \mathrm{CE}$ : Collision energy in electron Volts; ${ }^{4} \mathrm{RT}$ : Retention time in minutes; ${ }^{5}$ Ratio between quantification and confirmation ion response

\section{SPE procedure}

Due to the wide range in physico-chemical properties of the selected pharmaceuticals, 3 different SPE sorbents, $5 \mathrm{pH}$ levels and different combinations of elution solvents were tested during the method development and optimization. In sorbent selection, hydrophilic-lipophilic balance (HLB) and two ion exchange (Oasis MCX and Oasis MAX) polymeric sorbents were tested using $3 \mathrm{cc} / 60 \mathrm{mg}$ cartridges. The three sorbents are water-wettable and have wide range $\mathrm{pH}$ stability and hence appropriate for aqueous sample extraction. Oasis HLB is made from $\mathrm{N}$-Vinylpyrrolidine and divinylbenzene monomers which allow retention of hydrophilic and lipophilic compounds. Oasis MCX is dual sorbent made of mixed mode cation exchange sorbent comprising of sulfonic acid cation exchange and reversed phase retention groups. Oasis MAX is also a dual sorbent with a quaternary amine anion exchange and reversed phase retention groups. The basic SPE protocols for the three sorbents were used to establish the sorbent with the highest multiresidue recovery for the target analytes. The sample $\mathrm{pH}$ for Oasis MCX was lowered to enable formation the protonated species of the analytes for effective retention in the strong cation exchange sorbent and eluted at basic $\mathrm{pH}$ to enhance the desorption process. In contrast, the sample $\mathrm{pH}$ for Oasis MAX was raised to enable formation of anionic species and eluted at an acidic $\mathrm{pH}$. Oasis HLB was loaded and eluted at neutral $\mathrm{pH}$. The recoveries obtained for the three sorbents are shown in Figure 2. The best multiresidue retention capacity was observed with Oasis HLB with absolute recoveries for individual compounds ranging from 39\%-98\% while Oasis MAX and MCX recoveries ranged from $17 \%-95 \%$ and $14 \%-98 \%$, respectively. Significantly low recoveries for 3TC were obtained with Oasis MAX while MCX had low recoveries for TET and DOX. In 
general, the average total recovery for all the compounds combined was in the order; HLB > MAX > MCX.

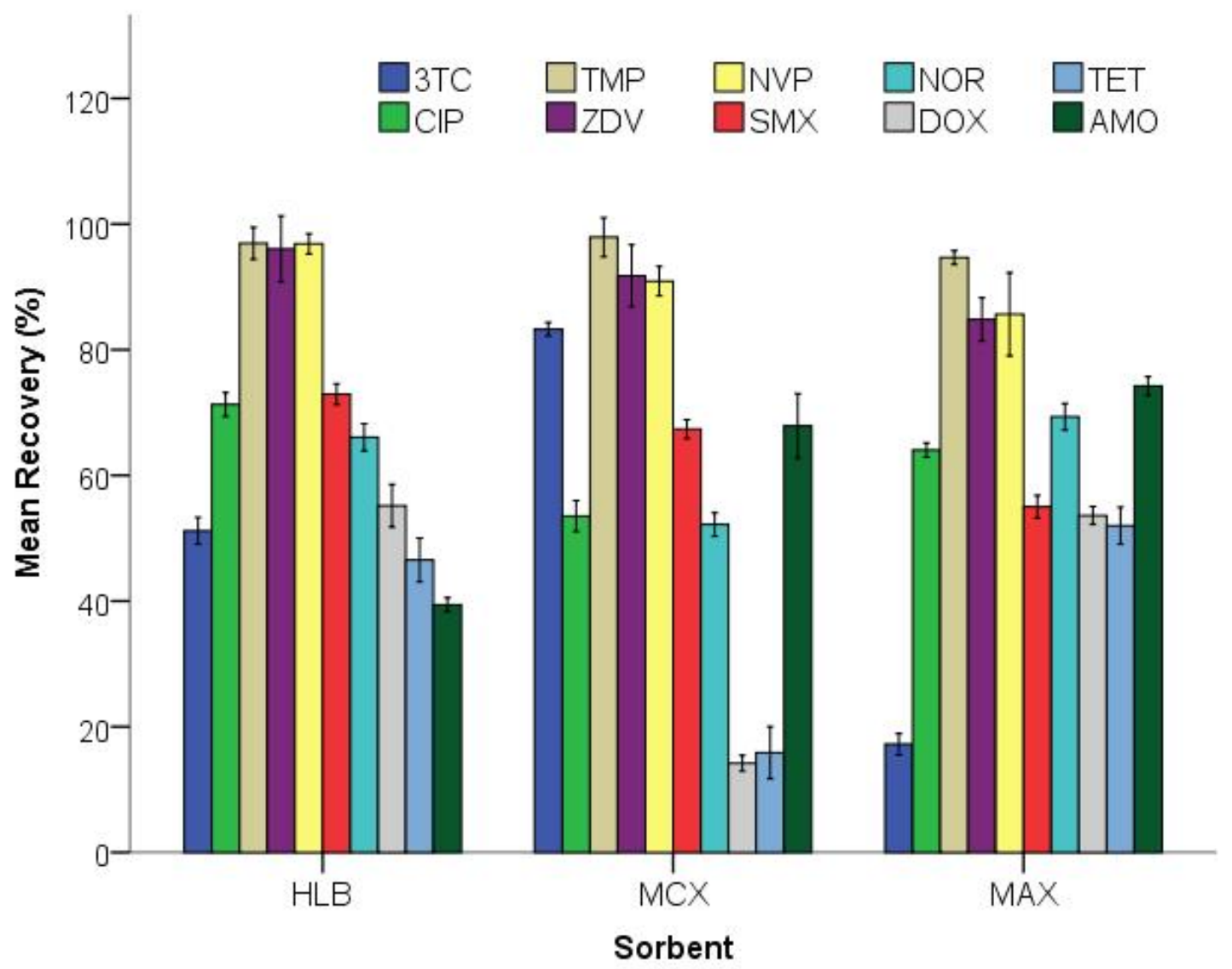

Figure 2: Percentage recovery for various adsorbents, the error bars are \pm 1 1SD

Sample $\mathrm{pH}$, elution solvent and elution volume were optimized for oasis HLB using surface water spiked with the target analytes. The absolute percentage recoveries obtained at different $\mathrm{pH}$ value are shown in Figure 3. The multiresidue overall average recovery was in the order $\mathrm{pH} 3>\mathrm{pH} 5>\mathrm{pH} 7>\mathrm{pH} 9>\mathrm{pH} 11$. The recovery was particularly low for $3 \mathrm{TC}$ at $\mathrm{pH} 3$ but gradually increased from $6 \%$ to $53 \%$ at $\mathrm{pH}$ 9. However, $\mathrm{pH} 5$ was selected as a compromise since higher $\mathrm{pH}$ resulted to significantly reduced recovery for SMX, DOX, TET and AMO. The highest recovery was achieved when $\mathrm{MeOH} / \mathrm{ACN}$ was used as the elution solvent while the optimum SPE elution volume for Oasis HLB (6 cc, $200 \mathrm{mg}$ ) was $4 \mathrm{~mL}$. In general, the combination of $\mathrm{pH} 5, \mathrm{ACN} / \mathrm{MeOH} 1 / 1(\mathrm{v} / \mathrm{v})$ and $4 \mathrm{~mL}$ offered the optimum sample $\mathrm{pH}$, elution solvent and elution volume respectively for Oasis HLB extraction of the selected antibiotics and antiretroviral drugs. 


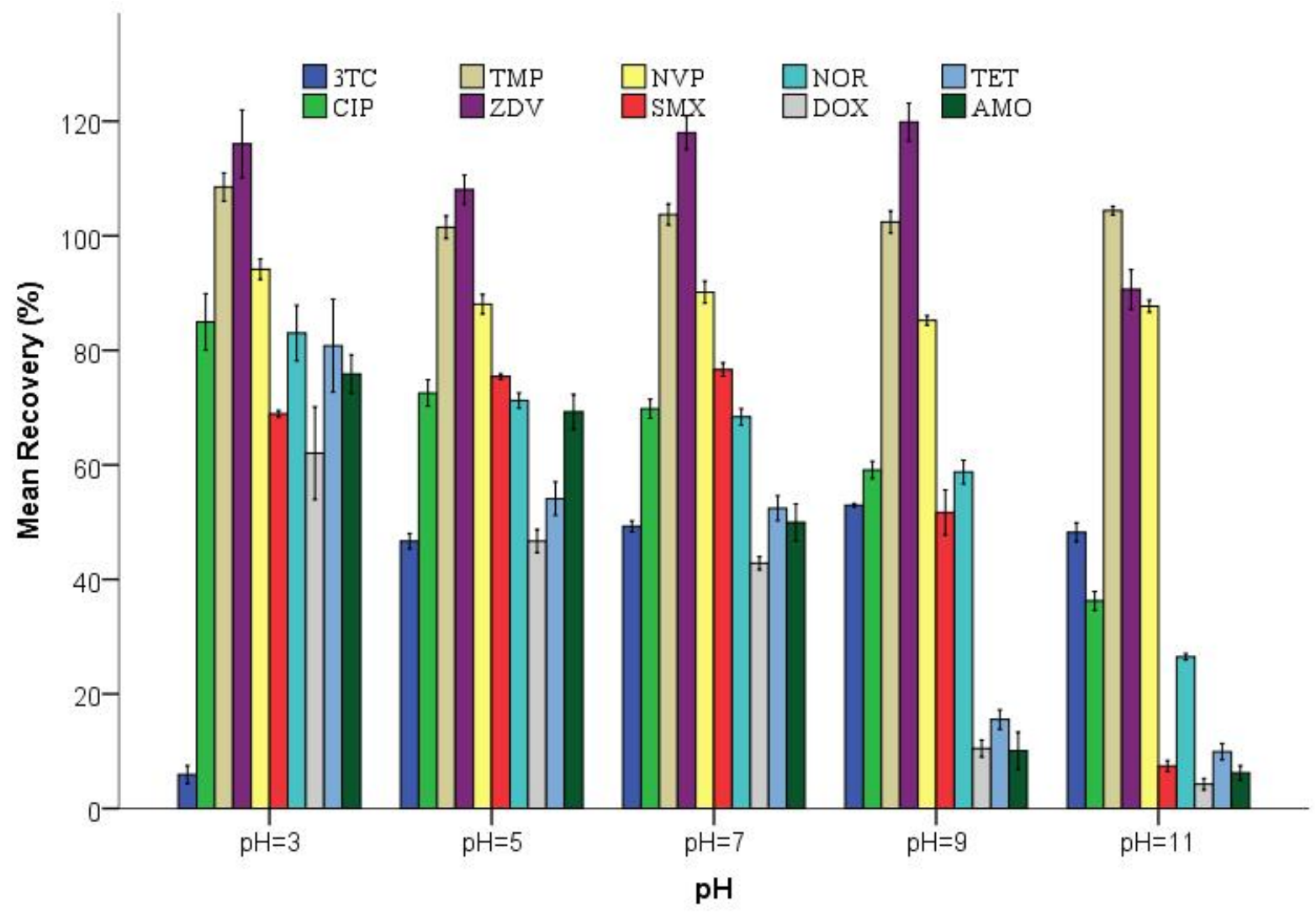

Figure 3: Recovery (\%) of target analytes spiked in lake water at different $\mathrm{pH}$ and extracted with Oasis HLB, the error bars are \pm 1SD

\section{Method validation}

The analytical parameters evaluated in the SPE-LC-ESI-MS/MS method included calibration, matrix effect, repeatability (precision), recovery, LOD and LOQ. Detection of pharmaceuticals using ESI-MS/MS has often been associated with considerable matrix effects leading to signal suppression or enhancement. To examine the possible matrix effects, the response of pure standards dissolved in the mobile phase were compared with that of matrix-matched standards. The matrix-matched standards were prepared by spiking analytefree surface water that had been subjected to the SPE process with the selected antibiotics and antiretroviral drugs. The observed matrix effects are as summarized in Table 3 . It is considered that no significant matrix effect is present when signal suppression or enhancement is less than $15 \%{ }^{38}$. In this study SMX, NVP, 3TC and TMP signal suppression/enhancement was not significant. However, the rest of the compound experienced enhanced matrix effect with ZDV having 33\% signal enhancement while AMO, TET, DOX and CIP had signal suppression of $17 \%, 30 \%, 26 \%$ and $20 \%$, respectively. The linearity of the response was determined by calculation the correlation coefficient of a series of calibration standards. The calibration curves obtained were linear for all the compounds over the whole calibration range with correlation coefficient $r^{2}>0.99$ (Table 3 and Supplementary material Figure S2).

The SPE-LC-ESI-MS/MS method repeatability was evaluated by computing the RSD values for interday precision at three spiking concentration levels. The results are as shown in the supplementary material Table S3. The RSD values ranged from 3-12\% and since the RSDs were $<15 \%$ the SPE-LC-ESI-MS/MS method was considered repeatable and reliable for 
subsequent analysis. The recovery of the analytes in the three water matrices ranged from 41$116 \%$ (Figure 4). The recovery for most compounds was above 50\% apart from 3TC, AMO, TET and DOX which had a maximum recoveries of less than $50 \%$ for WWTP influent and effluent. However, the recovery of the analytes was not expected to significantly affect the final quantification results since the calibration standards were also subjected to the extraction process. The method LOD and LOQ were calculated for each analyte using signal to noise $(\mathrm{S} / \mathrm{N})$ ratio. LOD and LOQ were computed at $\mathrm{S} / \mathrm{N}=3$ and 10 respectively. For all the analytes, the LOD and LOQ ranged from 2-18 ng/L and 5-63 ng/L, respectively (Table 3). The detection limits achieved in this study were considered adequate for trace analysis of aqueous environmental samples.

Table 3: Calibration, matrix effect, repeatability, LOD and LOQ for individual analytes in surface water

\begin{tabular}{|c|c|c|c|c|}
\hline Analyte & Linearity $\left(r^{2}\right)$ & $\begin{array}{c}\% \text { Matrix } \\
\text { effect (SD) }\end{array}$ & LOD (ng/L) & LOQ (ng/L) \\
\hline SMX & 0.9977 & $3(1)$ & 4 & 10 \\
\hline CIP & 0.9987 & $-20(1)$ & 2 & 7 \\
\hline NOR & 0.9962 & $-27(4)$ & 3 & 10 \\
\hline DOX & 0.9924 & $-26(3)$ & 13 & 44 \\
\hline TET & 0.9995 & $-30(4)$ & 3 & 9 \\
\hline AMO & 0.9994 & $-17(5)$ & 18 & 63 \\
\hline TMP & 0.9985 & $10(2)$ & 2 & 5 \\
\hline $3 \mathrm{TC}$ & 0.9985 & $8(1)$ & 2 & 6 \\
\hline ZDV & 0.9995 & $33(4)$ & 13 & 44 \\
\hline NVP & 0.9980 & $-5(2)$ & 2 & 5 \\
\hline
\end{tabular}




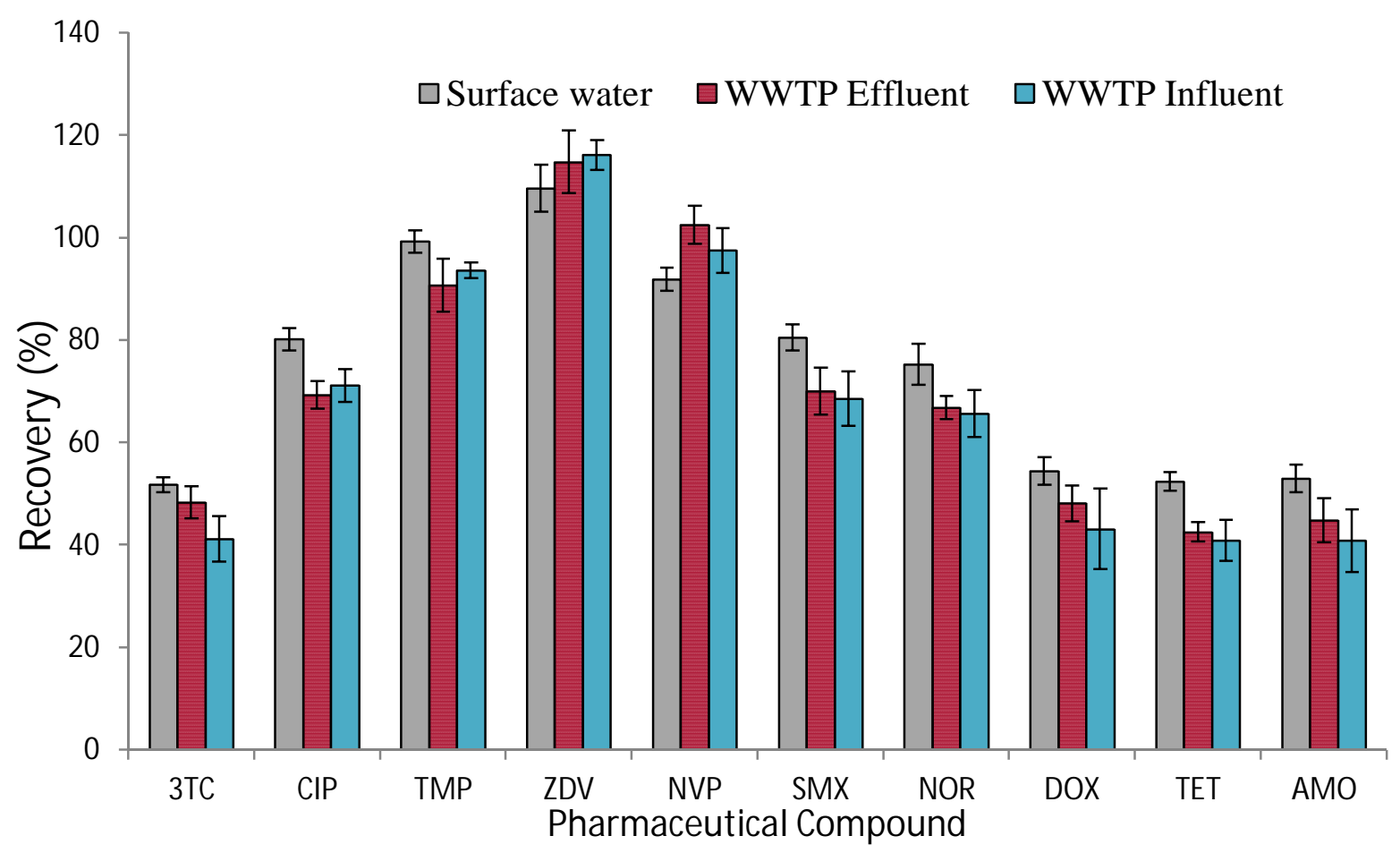

Figure 4: Percentage recovery at optimized SPE conditions for the surface water and WWTP influent/Effluent, the error bars are \pm 1SD

\section{Matrix-matched calibration VS the IS method}

The use of isotopically labelled internal standards is usually one of the most preferred in SPE-LC-ESI-MS/MS for correction of instrumental drifts, matrix effect and analyte losses during sample preparation since it is fast, simple and precise ${ }^{23,39,40}$. However, isotopically labelled compounds are usually expensive making them inaccessible to analysts working on limited budgets. In such a case, other methods such as external calibration, method of standard addition and matrix-matched calibration are used for quantification ${ }^{41}$. Most studies report use of matrix-matched calibrations constructed by spiking SPE extracts with the standards which only corrects for the matrix related errors. However, matrix-matched calibration constructed by spiking varying concentrations of target analytes in matrix and subjecting them through the whole sample extraction process can be effective in correction of matrix effect as well as sample preparation related loses in environmental analysis. This approach was adopted in this study by using surface water containing no detectable quantities of the target analytes for calibration curve construction.

Figure 5 shows the relative error (\%) for quantification of the some target analytes in surface water, WWTP influent and effluent using matrix-matched calibration with internal standard calibration as a reference. In this case, no comparison was made for AMO, TET and DOX since there were no suitable isotopically labelled surrogate standards at our disposal. For the surface water, the relative error ranged between $-6-+7 \%$ indicating a good agreement the two methods (where + and - error signify overestimation and under estimation, respectively, relative to the internal standard method). In the case of WWTP effluent and influent the error was significantly higher for some analytes and ranged from $-18-+4 \%$ and $-20-+4 \%$, respectively. The underestimation in the effluent and influent can be attributed to the difference in the recovery of the analytes in the three water matrices. However, the accuracy was within acceptable limits of between $-30 \%-+20 \%{ }^{42}$ and the matrix-matched calibration 
constructed from surface water can be used quantification of the analytes in the three water matrices with acceptable accuracy. However, the use of matrix-matched standards needs to be evaluated on a case by case basis to ascertain that all the analytical figures of merit have been fulfilled.

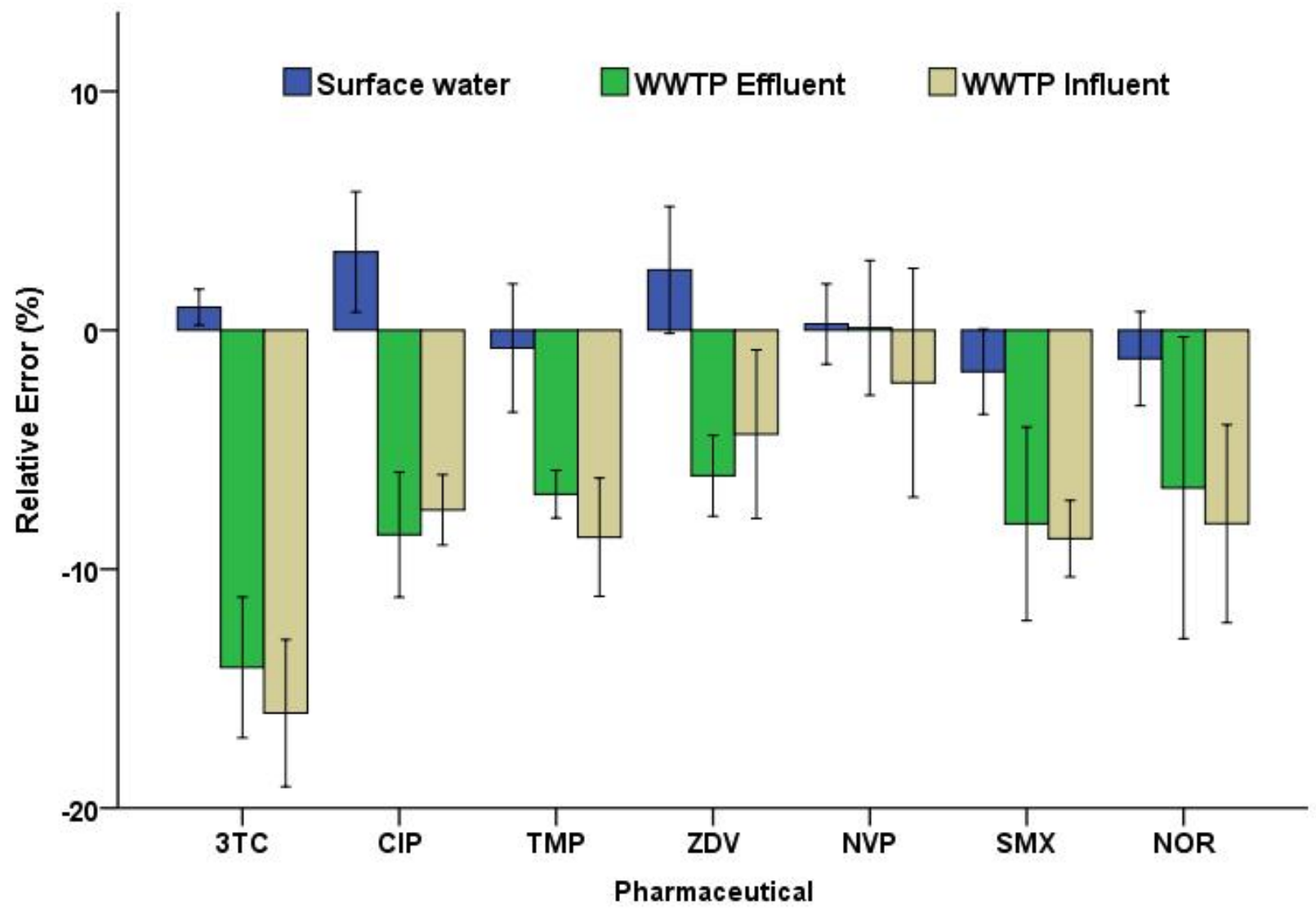

Figure 5: Percent relative error calculated based on the difference between matrixmatched calibration and internal standard quantification for some of the analytes in three water matrices whereby the positive and negative error represents overestimation and underestimation, respectively. The error bars are \pm 1SD

\section{Application to real samples}

The target pharmaceuticals were analysed from Jyväskylä municipal WWTP influent and effluent and the surface water from Northern Lake Päijänne to which the wastewater effluent is discharged to. The average concentrations for the target pharmaceuticals are summarized in Table 4 and Table 5 gives some reported concentrations of the analytes in various parts of the world.

\section{WWTP influent and effluent water}

All the measured antibiotics and antiretroviral were detected in both the influent and effluent waters of Jyväskylä WWTP. The concentration of the antibiotics in the wastewater during the two monitoring periods ranged from $29-570 \mathrm{ng} / \mathrm{l}$ and $16-538 \mathrm{ng} / \mathrm{L}$ in the influent and effluent wastewater, respectively. TMP had the highest concentration followed by CIP, NOR, SMX, AMO, DOX and TET. The concentrations the antibiotics in the influent was comparable to 
those previously reported in literature for example in Australia (TET: $\angle \mathrm{LOQ}-100 \mathrm{ng} / \mathrm{L}$; DOX:<20-650 ng/L; AMO: 190-280 ng/L) ${ }^{43,44}$, in Finland (CIP: 600 ng/L; NOR: 120 ng/L) ${ }^{45}$ and in Switzerland (SMX: 230-570; TMP: 210-440) ${ }^{46}$.

The removal of individual antibiotics by the WWTP during the two monitoring periods (September 2015 and March 2016) ranged from 10-76\% and 6-82\%, respectively. Overall, $40 \%$ and $44 \%$ of the studied antibiotics were removed from the aqueous phase, respectively. Poor removal of TMP was observed during the two study periods which can be attributed to possible deconjugation of metabolites during the wastewater treatment process as it has been observed in other similar studies ${ }^{47}$.

To the best of our knowledge, occurrence of antiretroviral drugs in the municipal influent and effluent wastewater has not yet been reported in Finland and very little data is available for the developed world which can be attributed to the low prevalence of HIV-AIDS. However, the current study confirmed the presence of the three target antiretroviral drugs with concentration of the influent and effluent ranging from 13-62 ng/L and 8-37 ng/L, respectively. ZDV had the highest measured concentration in both influent and effluent followed by 3TC and NVP. The influent concentrations of 3TC and ZDV were much lower than what has been reported in other countries for example in Belgium and Germany 507 $\mathrm{ng} / \mathrm{L}$ and $380 \mathrm{ng} / \mathrm{L}$ were measured for $3 \mathrm{TC}$ and ZDV, respectively ${ }^{16,17}$. The concentration of NVP reported in the current study compared the study by Prasse et.al. in Germany who reported mean influent and effluent concentration of $22 \mathrm{ng} / \mathrm{L}$ and $32 \mathrm{ng} / \mathrm{L}$ respectively ${ }^{17}$. The removal of the antiretroviral drugs in the WWTP ranged from 40-59\%. It can be noted that despite the low HIV-AIDS prevalence in Finland, the three antiretrovirals drugs constitute common treatment regimens that most patients take on daily basis ${ }^{48}$.

\section{Surface water}

The concentration of the antibiotics in the two sampling sites was much lower than in the WWTP effluent. The concentration ranged from <LOQ-54 ng/L with less than LOQ concentrations for DOX, AMO and TET which can be attributed to their low concentration in the effluent water and subsequent dilution after discharge into the lake. Sampling site A which is closer to the WWTP discharge point had relatively higher concentration of the detected antibiotics. It can therefore be concluded that the WWTP effluent is most likely the main source of antibiotics in Lake Päijänne. The concentrations of antibiotics in surface water reported in this study are comparable to other reported concentration in similar studies around the world as highlighted in Table 5.

Among the three antiretroviral drugs measured in this study, 3TC was the only detected drug at the sampling point closer to the WWTP discharge with a concentration of $11.5 \mathrm{ng} / \mathrm{L}$. Other similar studies have reported concentration of up to $167 \mu \mathrm{g} / \mathrm{L}$ for $3 \mathrm{TC}$ in some Kenyan surface waters ${ }^{49}$. Concentrations greater than LOQ in surface waters for ZDV and NVP have also recently been reported in Germany, South Africa and Kenya ${ }^{17,49,50}$. 
Table 4: Summary of the concentrations for the selected antibiotics and antiretroviral drugs in the Lake Päijänne and WWTP influent and effluent samples in ng/L

\begin{tabular}{ccccccc}
\hline \multicolumn{2}{c}{ Lake Päijänne } & \multicolumn{2}{c}{ WWTP Influent } & \multicolumn{2}{c}{ WWTP Effluent } \\
\hline & $\begin{array}{c}\text { Site A } \\
(\mathrm{n}=4)\end{array}$ & $\begin{array}{c}\text { Site B } \\
(\mathrm{n}=6)\end{array}$ & $\begin{array}{c}\text { September } \\
2015(\mathrm{n}=3)\end{array}$ & $\begin{array}{c}\text { March 2016 } \\
(\mathrm{n}=3)\end{array}$ & $\begin{array}{c}\text { September } \\
2015 \\
(\mathrm{n}=3)\end{array}$ & $\begin{array}{c}\text { March 2016 } \\
(\mathrm{n}=3)\end{array}$ \\
\hline SMX & $26(4)^{\mathrm{a}}$ & $14(3)$ & $184(11)$ & $220(8)$ & $74(11)$ & $111(12)$ \\
CIP & $52(7)$ & $34(8)$ & $410(33)$ & $429(36)$ & $165(2)$ & $77(9)$ \\
NOR & $54(19)$ & $22(5)$ & $209(15)$ & $242(34)$ & $99(22)$ & $98(10)$ \\
DOX & nd & nd & $56(3)$ & $54(6)$ & $20(2)$ & $16(1)$ \\
TET & nd & nd & $29(1)$ & $44(5)$ & $7(2)$ & $28(2)$ \\
AMO & nd & nd & $154(10)$ & $116(24)$ & $86(4)$ & $69(4)$ \\
TMP & $15(5)$ & $10(4)$ & $546(68)$ & $570(30)$ & $497(25)$ & $537(16)$ \\
& & Antiretroviral & & \\
ZDV & nd & nd & $46(6)$ & $62(8)$ & $22(3)$ & $37(6)$ \\
3TC & $12(2)$ & nd & $37(3)$ & $55(3)$ & $20(4)$ & $22(2)$ \\
NVP & nd & nd & $13(1)$ & $19(4)$ & $10(3)$ & $8(2)$ \\
\hline
\end{tabular}

${ }^{\mathrm{a}}$ Mean $( \pm \mathrm{SD}) ;{ }^{\mathrm{b}}$ nd: not detected 
Table 5: Selected antibiotic and antiretroviral concentrations reported in the literature

\begin{tabular}{|c|c|c|c|c|c|}
\hline \multirow[b]{2}{*}{ Analyte } & \multirow[b]{2}{*}{ Country/Region } & \multicolumn{3}{|c|}{ Concentration (ng/L) } & \multirow[t]{2}{*}{ Reference } \\
\hline & & Influent & Effluent & Surface water & \\
\hline \multirow[t]{4}{*}{ SMX } & Spain & $417.4^{b}$ & $73.0^{b}$ & $71.8^{b} ; 32-952$ & 51,52 \\
\hline & Switzerland & $230-570$ & $211-860$ & na & 46 \\
\hline & Sweden & $144-674$ & $135-304$ & na & 53 \\
\hline & Kenya & na & $1900-3340$ & $<$ LOQ-13765 & 54 \\
\hline \multirow[t]{4}{*}{ CIP } & Sweden & $90-300$ & $7-60$ & na & 53 \\
\hline & USA & $<$ LOQ-210 & $<$ LOQ-140 & na & 55 \\
\hline & Australia & $3800^{\mathrm{a}}$ & $640^{\mathrm{a}}$ & $<\mathrm{LOQ}-1300$ & 43,44 \\
\hline & Spain & na & na & $<\mathrm{LOQ}-224$ & 52 \\
\hline \multirow[t]{3}{*}{ NOR } & Sweden & $66-174$ & $<$ LOQ-37 & na & 53 \\
\hline & Finland & $<$ LOQ-960 & $<$ LOQ-110 & $<$ LOQ & 45,56 \\
\hline & Australia & $<$ LOQ -2200 & $<$ LOQ-2500 & $<\mathrm{LOQ}-1150$ & 43 \\
\hline \multirow[t]{3}{*}{ TMP } & USA & $7900^{\mathrm{b}}$ & $210^{\mathrm{b}}$ & na & 57 \\
\hline & China/Hong Kong & $120-320$ & $120-230$ & na & 47 \\
\hline & Spain & na & na & $38-690$ & 52 \\
\hline \multirow[t]{2}{*}{ DOX } & Sweden & 2480 & 880 & na & 53 \\
\hline & Australia & $<$ LOQ-650 & $<$ LOQ-150 & $<\mathrm{LOQ}-400$ & 43 \\
\hline \multirow[t]{3}{*}{ TET } & China/Hong Kong & $96-1300$ & $180-620$ & na & 47 \\
\hline & Belgium & $1658^{\mathrm{b}}$ & $<\mathrm{LOQ}$ & na & 16 \\
\hline & China & $16.5^{\mathrm{b}}$ & $1.9^{\mathrm{b}}$ & $2.1^{b}$ & 58 \\
\hline \multirow[t]{3}{*}{ AMO } & Australia & $<$ LOQ-6940 & $<\mathrm{LOQ}-50$ & $<$ LOQ-200 & 43 \\
\hline & India & $<\mathrm{LOQ}-172.6$ & $<$ LOQ-62.5 & na & 59 \\
\hline & UK & na & na & $39-245$ & 60 \\
\hline \multirow[t]{4}{*}{$3 \mathrm{TC}$} & Belgium & 507 & $<\mathrm{LOQ}$ & na & 16 \\
\hline & Germany & $720^{b}$ & $<\mathrm{LOQ}$ & $<\mathrm{LOQ}$ & 17 \\
\hline & South Africa & na & na & $132^{\mathrm{b}}$ & 50 \\
\hline & Kenya & $30300-60680$ & $19900-31070$ & $<$ LOQ-167100 & 49 \\
\hline \multirow[t]{3}{*}{ ZDV } & Germany & $380^{\mathrm{b}}$ & $564^{\mathrm{b}}$ & 170 & 17 \\
\hline & South Africa & na & na & $188^{\mathrm{b}}$ & 50 \\
\hline & Kenya & $12100-20130$ & $90-110$ & $<$ LOQ -17410 & 49 \\
\hline \multirow[t]{3}{*}{ NVP } & South Africa & $<\mathrm{LOQ}-2100$ & $<\mathrm{LOQ}-350$ & $177^{\mathrm{b}}$ & 50,61 \\
\hline & Germany & $21.8^{\mathrm{b}}$ & $32.1^{b}$ & $17^{\mathrm{b}}$ & 17 \\
\hline & Kenya & $850-3300$ & $1030-2080$ & $30-5620$ & 49 \\
\hline
\end{tabular}

${ }^{a}$ Median concentration; ${ }^{b}$ Mean Concentration; na: not analysed; <LOQ: less than limit of quantification or not detected

\section{Conclusion}

This paper describes development and validation of an SPE-LC-ESI-MS/MS method for simultaneous analysis of seven antibiotics and three antiretroviral drugs in surface water and municipal WWTP influent and effluent. The studied compounds have a wide range of physico-chemical properties that led to adoption of a number of compromises in order to achieve optimum multiresidue extraction. The SPE optimum recovery was achieved using oasis HLB with a sample pH 5 and an elution solvent consisting of ACN and $\mathrm{MeOH}$. Recovery for majority of analytes was above 50\% except AMO, 3TC, TET and DOX. The LOQ for the compounds ranged from 5-63 ng/L making the method sensitive enough aqueous environmental trace analysis. The method utilized matrix-matched standards to 
compensate for the matrix effect and sample preparation related loses. For the analytes whose isotopically labelled internal standards were available, the accuracy of matrix-matched calibration was evaluated relative to the internal standard method of quantification and was within $\pm 20 \%$ margin of error. Other analytical figures of merit such as calibration and precision were satisfactory to allow for the application of the method to environmental samples. The method was successfully applied in the analysis of the target residues in Lake Päijänne surface water and WWTP influent and effluent. The study revealed the presence of all the target analytes in the WWTP streams and surface water. The less frequently monitored antiretroviral drugs were measured in environmentally significant quantities especially in the WWTP streams which creates the need for broader comprehensive monitoring of these and other related compounds in other WWTPs and receiving surface waters.

\section{Acknowledgements}

This work was financially supported by the University of Jyväskylä Doctoral Program in Biological and Environmental Science and Maa- ja vesitekniikan tuki ry.

\section{References}

1 M. Carballa, F. Omil and J. M. Lema, Chemosphere, 2008, 72, 1118-1123.

2 M. Al Aukidy, P. Verlicchi, A. Jelic, M. Petrovic and D. Barcelò, Sci. Total Environ., 2012, 438, 15-25.

3 B. Kasprzyk-Hordern, R. M. Dinsdale and A. J. Guwy, Water Res., 2008, 42, 34983518.

4 T. Heberer, Toxicol. Lett., 2002, 131, 5-17.

5 C. S. McArdell, E. Molnar, M. J. F. Suter and W. Giger, Environ. Sci. Technol., 2003, 37, 5479-5486.

6 J. L. Martinez, Environ. Pollut., 2009, 157, 2893-2902.

7 K. Kümmerer and A. Henninger, Clin. Microbiol. Infect., 2003, 9, 1203-1214.

8 Y. Jiang, M. Li, C. Guo, D. An, J. Xu, Y. Zhang and B. Xi, Chemosphere, 2014, 112, 267-274.

9 S. Jain, P. Kumar, R. K. Vyas, P. Pandit and A. K. Dalai, Water. Air. Soil Pollut., 2013.

10 T. a Ternes, Water Res., 1998, 32, 3245-3260.

11 C. I. Kosma, D. a. Lambropoulou and T. a. Albanis, Sci. Total Environ., 2014, 466467, 421-438.

12 T. Zhang and B. Li, Crit. Rev. Environ. Sci. Technol., 2011, 41, 951-998.

13 J. Tang, T. Shi, X. Wu, H. Cao, X. Li, R. Hua, F. Tang and Y. Yue, Chemosphere, 2014.

14 S. T. Pynnönen and T. a. Tuhkanen, J. Sep. Sci., 2014, 37, 219-227.

15 NASCOP-Kenya, 2011, 4th ed., 230.

16 L. Vergeynst, A. Haeck, P. De Wispelaere, H. Van Langenhove and K. Demeestere, Chemosphere, 2014, 119, S2-S8.

17 C. Prasse, M. P. Schlüsener, R. Schulz and T. a. Ternes, Environ. Sci. Technol., 2010, 
44, 1728-1735.

18 M. Caban, N. Migowska, P. Stepnowski, M. Kwiatkowski and J. Kumirska, J. Chromatogr. A, 2012, 1258, 117-127.

19 J. Smeraglia, S. F. Baldrey and D. Watson, Chromatographia, 2002, 55, S95-S99.

20 T. M. Annesley, Clin. Chem., 2003, 49, 1041-1044.

21 F. Gosetti, E. Mazzucco, D. Zampieri and M. C. Gennaro, J. Chromatogr. A, 2010, 1217, 3929-37.

22 M. P. Lanuza, Universitat Rovira i Virgili, 2011.

23 E. Stokvis, H. Rosing and J. H. Beijnen, Rapid Commun. Mass Spectrom., 2005, 19, 401-407.

24 O. K. Ostroukhova and I. G. Zenkevich, J. Anal. Chem., 2006, 61, 442-451.

25 D. S. Wishart, C. Knox, A. C. Guo, S. Shrivastava, M. Hassanali, P. Stothard, Z. Chang and J. Woolsey, Nucleic Acids Res., 2006, 34, D668-72.

26 S. Babić, A. J. M. M. Horvat, D. Mutavdžić Pavlović and M. Kaštelan-Macan, TrAC Trends Anal. Chem., 2007, 26, 1043-1061.

27 USEPA and SRC, 2012.

28 M. Radke, C. Lauwigi, G. Heinkele, T. E. Múrdter and M. Letzel, Environ. Sci. Technol., 2009, 43, 3135-3141.

29 B. Kasprzyk-Hordern, R. M. Dinsdale and A. J. Guwy, Water Res., 2009, 43, 363-380.

30 F. E. Harlass, Prim. Care Update Ob. Gyns., 1996, 3, 58-62.

31 J. Straub, Antibiotics, 2013, 2, 115-162.

32 P. K. Jjemba, Ecotoxicol. Environ. Saf., 2006, 63, 113-130.

33 A. K. H. Kumar, G. Ramachandran, P. Kumar, V. Kumaraswami and S. Swaminathan, J. Int. AIDS Soc., 2006, 8, 53.

34 P. Riska, M. Lamson, T. Macgregor, J. Sabo, S. Hattox, J. Pav and J. Keirns, Drug Metab. Dispos., 1999, 27, 895-901.

35 Finnish Medicines Agency, Drug consumption in 2011 - 2014, Kuopio, 2014.

36 UNODC, 2009, 1-67.

37 M. Thompson, S. L. R. Ellison, A. Fajgelj, P. Willetts and R. Wood, Pure Appl. Chem., 1999, 71, 337-348.

38 B. Yilmaz, S. Arslan and V. Akba, Talanta, 2009, 80, 346-51.

39 K. Guo, C. Ji and L. Li, Anal. Chem., 2007, 79, 8631-8638.

40 R. N. Xu, L. Fan, M. J. Rieser and T. A. El-Shourbagy, J. Pharm. Biomed. Anal., 2007, 44, 342-55.

41 F. Hernández, J. V. Sancho, M. Ibáñez and C. Guerrero, TrAC - Trends Anal. Chem., 2007, 26, 466-485.

42 S. Yang, J. Cha and K. Carlson, J. Chromatogr. A, 2005, 1097, 40-53.

43 a. J. Watkinson, E. J. Murby, D. W. Kolpin and S. D. Costanzo, Sci. Total Environ., 2009, 407, 2711-2723.

44 A. J. Watkinson, E. J. Murby and S. D. Costanzo, Water Res., 2007, 41, 4164-76. 
45 N. Vieno, T. Tuhkanen and L. Kronberg, Water Res., 2007, 41, 1001-1012.

46 A. Göbel, A. Thomsen, C. S. McArdell, A. Joss and W. Giger, Environ. Sci. Technol., 2005, 39, 3981-3989.

47 A. Gulkowska, H. W. Leung, M. K. So, S. Taniyasu, N. Yamashita, L. W. Y. Yeung, B. J. Richardson, a. P. Lei, J. P. Giesy and P. K. S. Lam, Water Res., 2008, 42, 395403.

48 World Health Organization, Global Update on HIV Treatment 2013 : Results, Impact and Opportunities, WHO, Geneva, 2013.

49 K. O. K'oreje, L. Vergeynst, D. Ombaka, P. De Wispelaere, M. Okoth, H. Van Langenhove and K. Demeestere, Chemosphere, 2016, 149, 238-244.

50 T. P. Wood, C. S. J. Duvenage and E. Rohwer, Environ. Pollut., 2015, 199, 235-43.

51 S. Rodriguez-Mozaz, S. Chamorro, E. Marti, B. Huerta, M. Gros, A. Sànchez-Melsió, C. M. Borrego, D. Barceló and J. L. uis Balcázar, Water Res., 2015, 69, 234-242.

52 Y. Valcárcel, S. González Alonso, J. L. Rodríguez-Gil, a. Gil and M. Catalá, Chemosphere, 2011, 84, 1336-1348.

53 R. H. Lindberg, P. Wennberg, M. I. Johansson, M. Tysklind and B. A. V Andersson, Environ. Sci. Technol., 2005, 39, 3421-3429.

54 E. Ngumba, A. Gachanja and T. Tuhkanen, Sci. Total Environ., 2016, 539, 206-213.

55 K. G. Karthikeyan and M. T. Meyer, Sci. Total Environ., 2006, 361, 196-207.

56 N. M. Vieno, T. Tuhkanen and L. Kronberg, J. Chromatogr. A, 2006, 1134, 101-111.

57 A. L. Batt, S. Kim and D. S. Aga, Chemosphere, 2007, 68, 428-35.

58 A. Jia, Y. Xiao, J. Hu, M. Asami and S. Kunikane, J. Chromatogr. A, 2009, 1216, 4655-62.

59 P. K. Mutiyar and A. K. Mittal, Environ. Monit. Assess., 2014, 186, 541-557.

60 B. Kasprzyk-Hordern, R. M. Dinsdale and A. J. Guwy, J. Chromatogr. A, 2007, 1161, 132-145.

61 S. C. Mashiane M, J. Chromatogr. Sep. Tech., 2015, 06. 